(Aus dem physiologischen Institut des King's College in London.)

\title{
Über Beziehungen zwischen Zellstruktur und biochemischen Reaktionen. I.
}

Von

\section{Otto Warburg.}

Seit der Entdeckung der Zymase durch E. Buchner, H. Buchner und Hahn liegt es nabe, auch die physiologische Verbrennung als eine einfache Enzymreaktion aufzufassen.

Allerdings ist in Presssäften von Organen, die nach dem Buchner'schen Verfahren dargestelit sind, die Sauerstoffatmung: verschwunden ${ }^{1}$ ). Neue und sorgfältige Versuche stammen von Harden und Maclean $)^{2}$, aus denen gleichzeitig hervorgeht, dass die beim $\mathrm{Buchner}$ 'schen Verfahren zugesetzten Chemikalien, Sand und Kieselgur, nicht ohne Einfluss auf die Oxydationsprozesse sind.

Im Gegensatz zu der Hypothese, dass die physiologische Verbrennung ein einfacher enzymatischer Vorgang, wie die Zymasegärung, ist, stände etwa die Vorstellung, dass den geordneten ${ }^{3}$ ) Grenzflächen der Zellen, wie Plasmahaut, Kernmembran, Chromosomen-, Granulagrenzen usw. integrierende Bedeutung für die Oxydationsprozesse zukäme, sei es, dass verbrennliche Substanzen an diesen Grenzen, wie an der Oberfläche der Tierkohle, verdichtet würden, sei es, dass die Membranen ein Zusammenspiel chemischer Reaktionen vermittelten. Es sind das Vermutungen, wie ich sie früher gelegentlich ${ }^{4}$ ). im Anschluss an Experimente über Oxydationsbeeinflussung äusserte, und die erwarten liessen, dass nach Zerstörung der Zellstruktur die Atmung versehwindet.

1) In diesen Zusammenhang gehört vielleicht auch die Beobachtung von Fletcher und Hopkins, dass nach Zerstörung der Muskelfasern Milchsäure nicht mehr verschwindet. (Journ. of Physiol. vol. 35 p. 247.)

2) The Journ. of Physiol. vol. 43 p. 34.1911.

3) Geordnet wollen wir diese Flächen nennen im Gegensatz zu den Grenzflächen der Kolloidteilchen.

4) Untersuchungen über die Oxydationsprozesse in Zellen. Münchener ned. Wochenschr. Nr. 6. 1911. 
Versuche, hier $\mathrm{zu}$ entscheiden, ergaben bisher folgendes ${ }^{1}$ ): Bringt man Zellen (rote Blutzellen von Vögeln) durch Gefrieren und rasches Auftauen zum Zerplatzen, so bleibt unter geeigneten Bedingungen die Oxydationsgrösse auf unveränderter Höhe. Die mikroskopische Untersuchung der so behandelten Zellen ergibt, dass der Kern nicht oder sehr wenig verändert ist (Bilder in der betreffenden Arbeit loc. eit.), während der ganze flüssige Inhalt des Protoplasmas ausgetreten ist. Wir können uns das anschaulich so vorstellen, dass durch das plötzliche Auftauen die Plasmahaut durchlöehert wird. Zentrifugieren der zerstörten Zellsuspension zeigt, dass nicht in der Flüssigkeit, sondern in den abzentrifugierten Formelementen, d. h. Kernen plus nichtflüssigen Protoplasmagerüsten, der Sauerstoff verzehrt und die Kohlensäure gebildet wird. - Die starke Atmung zerstörter Zellen wird nur beobachtet, wenn in der verwendeten Suspension Zelle neben Zelle liegt; ist viel Zwischenflüssigkeit vorhanden, wie Serum oder Ringer'sche Lösung, so wird nach Zerstörung der Plasmahaut viel weniger Sauerstoff verbraucht.

Es gelingt nun leicht, die Formelemente, die nach Zerplatzen der Plasmahaut zurückbleiben, mit chemischen Mitteln völlig zu zerstören. Doch ist damit zur Entscheidung unserer Frage wenig gewonnen, weil sich die chemische von der strukturzerstörenden Wirkung nicht trennen lässt; der Versuch ist nur rein, wenn die Struktur allein auf mechanischem Weg, ohne Zusatz irgendwelcher Substanzen oder Verdünnungsflüsigkeiten, vernichtet wird. Nach vergeblichen Bemühungen, das mit Hilfe des Apparates von Macfadyen und Rowland ${ }^{2}$ ) zu erreichen, gelang das ausgezeichnet in der von $\mathrm{B}$ ar $\mathrm{n}$ ard und $\mathrm{Hewle} \mathrm{t}^{3}$ ) angegebenen Anordnung, mit der man in kurzer Zeit eine genügende Menge Material so völlig zerkleinern kann, dass unter dem Mikroskop keine Struktur mehr zu erkennen ist.

Es hat sich ergeben, dass nach Zerstörung der Struktur die Atmung aufhörte.

1) Hoppe-Seyler's Zeitschr. f. physiol. Chemie Bd. 70 S. 413.1911.

2) Zentralbl. f. Bakteriol. 1903 Nr. 8. - Exzellenz Ehrlich, der mir den Apparat geliehen bat, spreche ich auch hier meinen besten Dank aus. Ebenso Herrn H. Dale, der mir erlaubte (in Wellcome Physiological-Research Laboratorium, London) einen Versuch mit dem Macfadyen'schen Apparat zu machen.

3) Proceedings of the Royal Society B. vol. 84. 1911. 


\section{Versuche ${ }^{1}$ ).}

Das Prinzip des Apparates von Barnard und Hew lett besteht darin, dass in einem rotierenden Stahlgefäss Stahlkugeln rotieren; durch eine feste Achse wird erreicht, dass die Kugeln langsamer rotieren als das Gefäss; die Zerkleinerung geschieht dann an der Berührungsfläche der Kugeln mit dem Gefässinnern.

$15 \mathrm{~cm}$ einer möglichst konzentrierten Suspension von Gänseoder Hühnererythrocyten in Serum (erhalten durch starkes Zentrifugieren von defibriniertem Blut) wurden in der Regel in den Apparat gebracht, der 10-20 Minuten in Gang blieb.

Ein sehr wesentlicher Vorteil des Apparates ist, dass infolce der geringen Reibung die Temperatur nur ganz wenig ansteigt. Fängt man mit Blut von $20^{\circ}$ an, so ist nach Beendigung des Versuches die Temperatur ca. $24^{\circ}$. - Eine Temperatur über $40^{\circ}$, auch wenn sie lokal nur kurze Zeit einwirkte, würde die Beweiskraft des Versuches natürlich sehr vermindern; es wurde deshalb meist gekühlt, ausserdem das Blut in Eis vorgekühlt; so erreicht man leicht, dass die Höchsttemperatur, direkt nach Anhalten des Apparates, $8-10^{\circ}$ beträgt.

Die zerkleinerte Masse musste zur Entfernung von Luftblasen einige Minuten zentrifugiert werden; dann wurde sie in verschlossenen Gefässen 1-2 Stunden bei $37^{\circ}$ gehalten und darauf, stets in $2 \mathrm{~cm}$, im B a r c r of t' schen Apparat der verschwundene Sauerstoff bestimmt ${ }^{2}$ ). Um nicht die leicht schäumende Flüssigkeit stark an der Luft zu schütteln, wurde die Druckverminderung vor und am Ende der Atmung bestimmt; unter $p$ ist im folgenden, wie stets ${ }^{2}$ ), die Differenz der Druckverminderungen verstanden, unter $t$ die Bestimmungstemperatur, unter $v$ das Volumen, in dem die Druckverminderune auftrat. Der Fehler einer Differenzbestimmung ist etwa $6 \mathrm{~mm}$ (für jede Bestimmung $3 \mathrm{~mm}$ ). Dementsprechend liegt ein Ausschlag von \pm 6 innerhalb der Fehler. - Gleichzeitig wurde stets der Sauer-

1) Die Blutentnahmen wurden, unter Anwendung von etwas Cocain, in Übe1einstimmung mit dem englischen Gesetz vorgenommen. Herr Professor Halliburton, der die vorgeschriebene Lizenz hatte, wohnte den Blutentnahmen bei. - Herrn Professor Hewlett danke ìch auch hier für die Erlaubnis, dass ich den von ihm konstruierten Apparat in seinem Laboratorium benutzen durfte.

2) Einzelheiten bezüglich Sauerstoffbestimmung siehe Hoppe-Seyler's Zeitschr. f. physiol. Chemie Bd. 76 S. 331. 1912. 


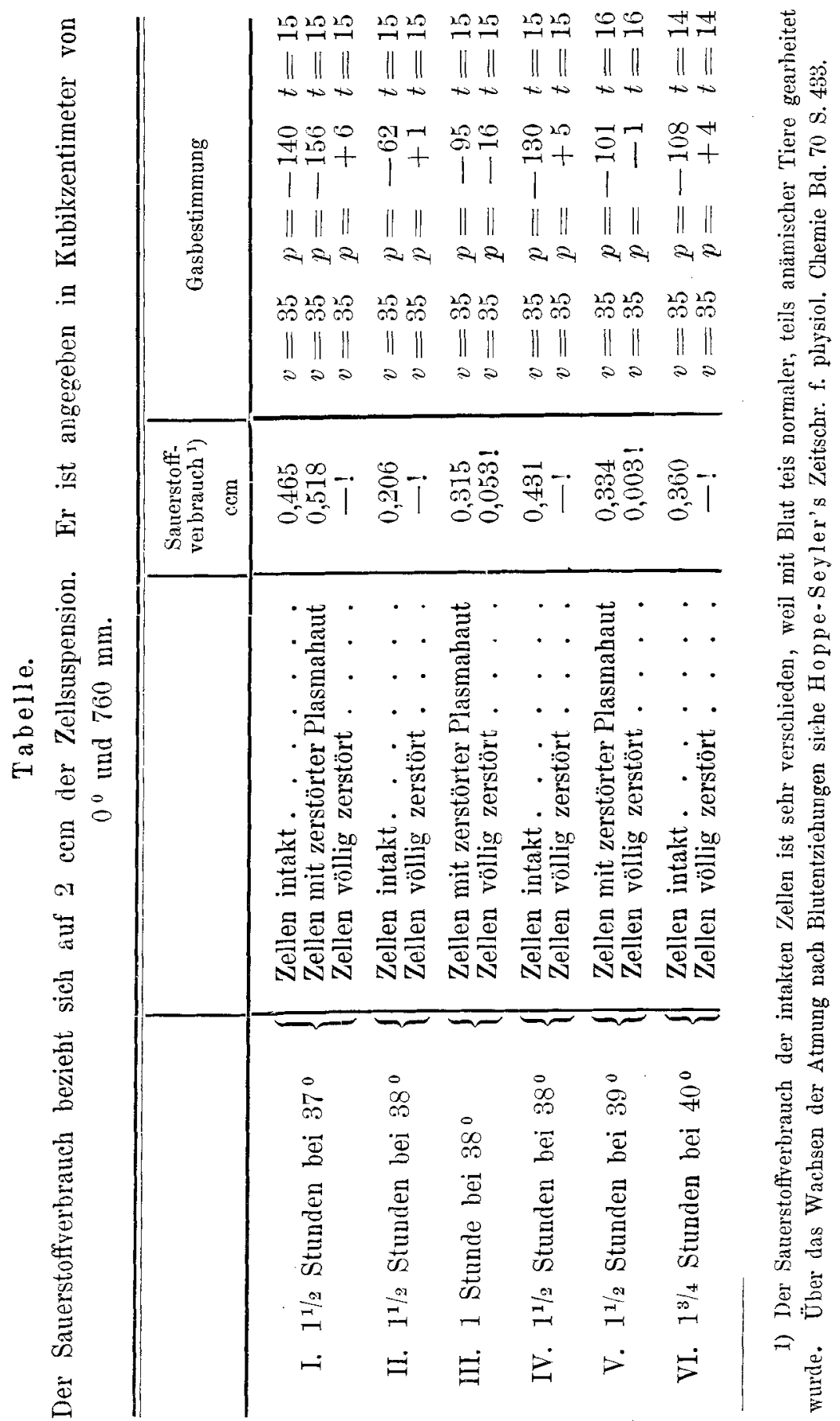


stoffverbrauch derselben Suspension, nicht zerkleinert oder nur mit gesprengter Plasmahaut, gemessen.

(Siehe Tabelle auf S. 280.)

Die Zahlen bedürfen keiner Erläuterung. In Versuch III ist die Atmung nicht völlig verschwunden, sondern nur auf ein Sechstel gesunken, von neun Versuchen der einzige, in dem noch eine deutliche Sauerstoffabsorption beobachtet wurde. Immerhin ist der Abfall auch hier sehr erheblich.

Die Behauptung, dass nach dem Zerkleinern die Sauerstoffzehrung verschwindet, bezieht sich natürlich nur auf die angegebene Zeit und hat auch nur Sinn, wenn man weiss, wieviel die intakten Zellen in der gleichen Zeit verbrauchen. Es ist kaum zu bezweifeln, dass für jedes derartig komplizierte Gemisch organischer Substanzen eine Zeit existiert, innerhalb deren Sauerstoffabsorptionen messbar werden.

Zum Schluss sei kurz die Möglichkeit besprochen, dass die Aufhebung der Atmung nicht von der mechanischen Zerstörung, sondern vielleicht von Metallspuren herrührt, die während des Zerkleinerungsprozesses in die Zellsuspension hineinkommen (also etwa Eisen). Wahrscheinlich ist das schon deshalb nicht, weil Eisen in bikarbonathaltigen Flüssigkeiten auch in ziemlich grosser Menge wirkungslos ist ${ }^{1}$ ), weil ferner unsere Suspensionen viel Eiweiss enthalten, das die Metallwirkung erheblich schwächt. Trotzdem habe ich die folgenden zwei Kontrollen gemacht: 1. ein Teil der stark atmenden Suspension mit zerstörter Plasmahaut wurde mit etwa zwei Teileu der gänzlich zerkleinerten, nicht atmenden Suspension gemischt. In dieser Mischung wurde keine Abnahme der Atmung beobachtet, sondern im Gegenteil eine Zunahme ${ }^{2}$ ). Dieses Resultat wurde zweimal erhalten. Will man nicht annehmen, dass beide Male zufällig nur so viel "Gift" in der gänzlich zerstörten Suspension war, dass es genügte, die Atmung aufzuheben, aber keine Spur, um die Atmung weiter zugesetzter Zellen auch nur zu vermindern, so spricht dieser Versuch ungemein zuungunsten einer Giftwirkung. 2. Eine konzentrierte Suspension von Bacillus prodigiosus in Boullion wurde der nichtatmenden, völlig zerstörten

1) Hoppe-Seyler's Zeitschr. f. physiol. Chemie Bd. 66 S. 319.

2) Die z. B. daher kommen könnte, dass der Hämoglobinvorrat, der den atmenden Elementen zur Verfügung steht, grösser wird durch das Mischen mit nichtatmender Suspension. 
282 Otto Warburg: Über Beziehungen zwischen Zellstruktur etc.

Suspension zugesetzt. Die sehr erhebliche Druckverminderung am Manometer, nach - einstündiger Inkubation bei $37^{\circ}$, zeigte starke Atmung an, sodass auch der Einwand hinfällig wird, das Oxyphämoglobin sei in einen Zustand übergeführt, in dem es keinen Sauerstoff mehr abgibt.

Ich halte es mithin für ungemein wahrscheinlich, dass allein die mechanische Zerkleinerung der Blutzellen genügte, um die Sauerstoffatmung aufzuheben; doch seien die verschiedenen Deutungen, die der Ausfall des Experimentes zulässt, zunächst nicht diskutiert.

Die Ausführung dieser Experimente wurde mir durch ein Reisestipendium von der Jagor-Stiftung in Berlin ermöglicht. 